\title{
Legal disputes and building defects: some data from Tuscany (Italy)
}

\author{
Mauro Sassu, DESTEC - Department of Energy, Systems, Territory and Constructions Engineering, \\ University of Pisa,Italy-m.sassu@unipi.it
}

Anna De Falco, DESTEC - Department of Energy, Systems, Territory and Constructions Engineering, University of Pisa ,Italy - a.defalco@ing.unipi.it

\begin{abstract}
This paper reports on a wide-ranging research study conducted on the Interim Technical Assessments (I.T.A.s) drawn up for law suits over defective constructions in Tuscany from 2000 to 2011. It provides a set of statistically significant data to highlight the impact of construction defects in buildings and evaluate their origins and the responsibilities of the technical personnel involved. The data have been classified according to various categories based on the type of damage encountered. Analysis of the most common types (in particular, water damage) and comparisons with the data from a similar survey carried out in the decade 1990-1999 provide indications as to the critical aspects deserving of special attention, including building design and inspections during construction. Such analysis can provide useful information for assessing whether the quality of construction has kept pace with new knowledge and advances in technology.
\end{abstract}

\section{INTRODUCTION}

The dissemination of failure-related information, mainly in the sector of civil engineering and architecture, is crucial for improving our knowledge of the building construction process. An important source of information on such failures is represented by the archives of district court judgements. In fact, the filing of law suits are the typical means by which resentful home- 
owners seek redress for being sold a defective construction. The number of such legal actions taken provides an objective measure of the failures in the construction process. It is moreover of interest in identifying the stage at which such failures come about. Indeed, during these legal proceedings, technical consultants to the parties and court-appointed technical experts ensure thorough investigation of the facts, and formulate well-founded assessments of the damages, their causes and possible remedies.

The court archives, containing the proceedings and sentences of such cases, thus represent an extremely useful source for uncovering the critical aspects of modern buildings and assessing whether and how recent advances in construction techniques, materials, and knowledge have translated into corresponding advances in the quality of the final products - buildings.

An Interim Technical Assessments (I.T.A.) is an instrument in the Italian Justice system for quickly determining the nature and origin of building defects after a complaint by the injured party and before the civil lawsuit: a technician appointed by the judge is assigned the task of describing the defect, taking a sort of "photo" of the situation. Recently, the tasks of I.T.A. technicians have been broadened to include identifying the causes of the defects and proposing an agreement to solve the litigation. This procedure is motivated by the necessity, in most cases, to provide for quick repair operations to protect other aspects of the constructions or to avoid the defects causing further damage. In any case, in order for such a legal dispute to proceed, before any repairs are made, it is necessary to have an impartial description of the status quo, drawn up by a technician extraneous to the event and trusted by the judge, in order to avoid any alteration of the relevant technical and legal data.

These technical reports thus represent a valuable unbiased database for analyzing the most recurring defects in the sector of civil constructions. In this sense, the engineer (or better, the Forensic Engineer) plays the role of expert and impartial witness for disseminating information to the community of technicians and regulators. 
Various ways to classify the main defects have been previously studied by other authors, as Matousek \& Schneider, Yates \& Lockley, or Carper et al. Particularly Matousek \& Schneider (1976 and 1997) examined about 800 cases of defects, Yates \& Lockley (2002) considered a large number of data from Occupational Safety and Health Administration. Carper (2002) identified the main stages at which errors are committed: a) conceptual planning, b) design, c) construction, d) maintenance. Extreme natural events, such as floods, fires, impact loads or vibrations, typhoons and earthquakes, can exacerbate defects in constructions: incorrect conceptual planning or design (or in some cases, an inefficient system of regulation) can produce devastating effects in urban contexts. The recent examples of the Abruzzo (2009) and Emilia (2012) earthquakes in Italy reveal the effects of inefficient planning of the urban areas and improper evaluation of the seismic hazard. In Abruzzo a 300-year earthquake (similar to an event in 1703) occurred in 2009. It was actually was expected by geologists and even preceded by three months of seismic swarms. Moreover, the damages to the cultural heritage testify to how, after two centuries, public attention to the possibility of an earthquake waned, producing a "biological effect" of "malformations and monstrosities" in pre-engineered buildings, as described by Drdack and Kratena (2000). In the Emilia region the 500-year earthquake in 2012 surprised a rich industrialized area, damaging or destroying a large portion of its prefabricated industrial buildings containing important warehouses, whose economic value amounted to a thousand times the costs of reconstruction, and a staggering million times the operational costs of rendering steel joints or r.c. precast frames seismically resistant: the problem was thus not economic, but mainly cultural.

Also design errors, due in some cases to inadequate procedures in deciding on structural details and the lack of quality control in technical drawings can lead to collapse. Some famous failures demonstrate that some times the fault lies in a surprising lack of controls, as stated by Kaminetzky (1991) and Bosela et al. (2007). The construction phase often sets the stage for 
failure, mainly due to incorrect evaluation of temporary supports or construction loads, or erroneous selection of materials, as reported by Feld \& Carper (1997). Moreover the presence of latent defects in buildings due to improper design can induce relevant damages, as studied by Chong \& Low (2006) through a set of 79 civil constructions. Finally, maintenance is not only the responsibility of building owners and operators: the need to practice proper usage and maintenance should be strongly emphasized by designers in drawings and technical documents (Zaffagnini, 1991). Lastly, another cause of defects is due to the "complexity" that characterizes the construction process (Arangio et al., 2010): the different susceptibility to errors of the various stages of construction should be properly analyzed and each stage monitored accordingly.

The dissemination of information on failure events, with detailed descriptions of the causes, is crucial to preventing further failures: a collapse is certainly an undesired event, often with serious consequences, but it can help avoid many others if correctly explained and information on its causes disseminated. Monographs (Carper, 2001 or Ratay, 2000), University Courses (De Witt et al, 2001) and Proceedings (Augenti, IFCRASC'09 or Augenti \& Sassu IFCRASC'12) represent important instruments for educating architects and engineers against errors.

This work deals with construction defects that have led to litigation. In many cases the defects in question were apparently minor and fortunately never produced tragic events, but they do regard a large number of buildings, reducing their efficiency and causing relevant socioeconomical damage to the citizens and companies involved in the construction process (Gucci, De Falco \& Sassu, 2003). Approximately 120 Interim Technical Assessments (I.T.A.s) in the Pisa district court regarding the years 2000-2011 (Cellesi, De Falco \& Sassu, 2012) have been examined. We provide an overview of the statistically most frequent construction flaws in buildings and their causes. The statistics have been further supplemented by about 200 civil 
disputes undertaken in the years 1990-1999 in the Pisa, Livorno and Lucca district courts from Gucci et al., $(1998,2002)$ in order to identify and classify the most common defects in civil constructions and make comparisons with the more recent data.

The study thus furnishes a panorama of building quality in Tuscany over the last twenty years, though the data presented can be assumed indicative of all of Italy. It moreover serves to highlight the potentials of the proposed method of study, whose application on a wider scale would certainly yield some interesting insights.

\section{BUILDING DEFECTS}

The causes of dissatisfaction of the buildings' inhabitants vary widely, ranging from partial or total collapse, to cracking, improper systems functioning, finishing flaws, inadequate acoustic insulation, poor climate control, water infiltration, and premature degradation of the building materials. Apart from collapse, many defects manifested themselves through the presence of water, whether from inadequate protection of exterior surfaces, insufficient or poor insulation or capillary action. In this regard, figure la shows the most often occurring defects encountered in buildings.

Fig. 1 a) Most frequent construction defects linked to the presence of water; b) Surface decay due to driving rain In particular, the efficiency of the drainage system is crucial: when gutters and downspouts become clogged or fail, rainwater flowing down house walls can cause a great deal of damage, contributing to the decay of siding and the house's structure. Similarly detrimental is the absence of eaves that ensure protection of the facades against rain. Figure $1 \mathrm{~b}$ shows a water damaged facade. Moreover, the humidity after rains evaporates, thereby subtracting heat from and increasing the thermal transmittance of the walls (Cirillo 1985 - Gucci et al, 1997). In addition, even without the penetration of rainwater, the dampness can produce condensation and mould on the upper parts of the building, (fig. 2). 
Fig. 2. Modern roof terrace (with water damage) and surrounding traditional pitched roofs (without problems)

Instead, the overhang of the eaves of a pitched roof determines an aerodynamic effect, like a "spoiler", which keeps the rain away from the surfaces. Modern architectural trends call for the adoption of flat roofs to enable the addition of terraces, roof gardens, etc., though such designs call for particular attention to all details regarding the removal of water, together with proper selection of materials and careful inspection of the work. Moreover, perimeter walls must be well connected to the roof to prevent water penetration. In this regard, one recurring defect cited was water penetration from a roof terrace. Figure 2 shows the moisture determined efflorescence on the top of a building after wind-driven rain. The traditional roof shapes in low-rise buildings are pitched, gable or hip type to permit the outflow of rain and sliding off of snow: in such cases ensuring perfect water tightness is unnecessary.

Proper design of the rainwater drainage from underground garages is crucial to avoid penetrations: in many cases defective drainage systems from unsuitable design of air ducts and/or protection from rain (fig. 3). Another frequent cause for litigation was inappropriate selection of materials to use in buildings, often in ordinary elements such as clay units, plaster or concrete. Moreover, in most cases repairing such defects requires demolition and reconstruction (fig. 4).

Cracking and deformation phenomena are often the subject of legal action, even if they do not always lead to collapse or serious structural consequences. Such phenomena are generally attributable to excessively slender horizontal load-bearing structures, to renovations by the home-owner that alter the building's structural integrity or frequently to disturbances to the foundation ground due to excavations under or in the proximity of the building. In all such cases, defects arise both in new, as well as old buildings for different reasons depending on the construction materials used. 
Fig.3. Improper disposal of rainwater in underground garage and efflorescence on an r.c. ceiling.

Finally, some collapses are linked to the lack of accurate assessment of the structural integrity of existing buildings. A common misconception, held by both private and public owners, is that historical constructions are "self-tested" by age. This often leads to underestimation of the seriousness of cracking patterns. In the case shown in figure 5 excessive rainfall determined the failure of recently restored base walls, due to the absence of scuppers.

Fig.4. Erroneous selection of clay units (left), concrete (upper right) or plaster (lower right)

Fig.5. Unassessed structural integrity of historical tower (collapsed after heavy rain)

\section{CLASSIFICATION OF DATA}

A first general classification covers the most common causes of building problems, with the sole aim of investigating the alleged damage, regardless of building type, its intended use, the time of construction or the construction techniques employed. The more detailed subdivision that follows further distinguishes whether the defect occurred in existing or new buildings. The basic classes are as follows:
a. water damage (leaks, seepage, infiltration);
b. cracking;
c. systems failure or non-compliance (electrical, heating, plumbing);
d. defective finishing (windows, metalwork, facings);
e. dampness from condensation;
f. non-compliance with acoustic requirements;
g. partial or total collapse;
h. structural settlements. 
The most frequent types of defects cited in the law suits are water damage and cracking. Accordingly, the respective categories have been further divided according to the origin and location of the defect. Water damage has been subdivided in terms of source into:

al basement or ground floor;

a2 high walls (i.e., of the upper floors);

a3 roof terraces;

a4 pitched roofs;

a5 balconies;

a6 breaking or leaking pipes;

Cracking phenomena have similarly been distinguished according to location:

b1 plasterwork;

b2 floors;

b3 walls;

b4 horizontal elements (e.g., ceilings);

b5 beams, columns, and arches.

Although corresponding subclasses could be devised for each of the remaining categories, we have opted to omit them: the amount of case studies available for each is considerable, though it is not so high as to allow for drawing any statistically significant conclusions. The available data were compiled according to the period of the complaint, essentially to divide the types of defect within a grid containing the defects cited in each I.T.A. Table 1 shows an excerpt for the years 2000-2003.

Table 1. Defect types reported in each ITA (2000 to 2003 extract).

\author{
ANALYSIS OF RESULTS \\ Percentage distributions of defects
}


Some first findings of general interest are shown in Figure 6, which reports the percentage frequency of each type of construction flaw, according to the above classification, expressed out of the total number reported (222) in all the 120 I.T.A.s examined in the province of Pisa. Clearly, the problem of water damage $(48.6 \%)$ is the one most commonly affecting buildings, especially new ones, its incidence being more than twice that of the second most frequent, cracking phenomena (23.4\%). Looking at the individual damage categories, it is moreover possible to subdivide the defects encountered according to their main causes and locations, as is done in the following.

Fig. 6: Percentage distribution of construction defects reported in the district of Pisa 2000 - 2011.

\section{Damage categories}

Water damage

As stated, water damage is the most often cited for both new and old buildings and, not surprisingly, often leads to other problems of various types. Figure 7 shows the frequency distribution of the source concerned.

Fig. 7. Percentage distribution of water leak defects according to source.

Leakage from flat and pitched roofs, taken together, is clearly the most common source of water damage (18.5\% for plane and $23.1 \%$ for pitched). It has also been noticed that in newer buildings, seepage arises mainly from the ground due to capillary action (39.5\%), while in older buildings leaks are most often linked to imperfections in the roofing $(50 \%$ overall, including $27 \%$ for pitched roofs and $23 \%$ for flat, as compared to $26.8 \%$ for capillary action). The problem of capillary water rise can be attributed to insufficient insulation, which is often due to improper design or construction. Figure 8 shows the percentage distribution of the major causes of water infiltration in the basement and ground floor. 
Fig. 8. Percentage distribution of the major causes of water damage to basement and ground floor.

With regard to roof leaks, in terracotta-tiled pitched roofs the fault lies mainly at the points of convergence of areas in different planes (ridges and valleys), the connections between roof and walls, and at the base of chimneypots. As in the case of industrial building roofs, which are usually composed of metal or plastic panels laid flat, overlapping areas of panels are the critical points of the system; such panels should be tightly adherent and properly sealed to avoid any effect on the building. Figure 9 instead shows the most frequently occurring causes of leaks in pitched roofs.

Fig. 9. Percentage distribution of main causes of leakage in pitched roofs.

Most leaks from flat and terrace roofs are attributable to either the waterproofing system, the channels for rainwater drainage or the slope of the terrace floor. Figure 10 shows the percentage distribution of the major causes of leaks revealed in such roofs during the survey: seepage onto upper walls occurs in almost all cases in modern buildings, which are generally wholly lacking overhanging eaves, as previously illustrated in the examples.

Fig. 10. Percentage distribution of main causes of water damage in flat roofs.

Also relatively common causes of rain penetration from balconies are ineffective waterproofing of the terrace floor and insufficient slope, often exacerbated by inefficient systems of ducts for rainwater runoff.

\section{Cracking}

Cracking phenomena are found equally often in structural elements, both load-bearing and non (walls, ceilings, beams, columns and arches), as well as in facings, such as plasterwork and floor and wall tiles. Figure 10 shows the percentage distribution of the location of cracks.

Figure 11. Partial incidence of crack location. 
Non-load-bearing walls most often undergo more cracking with respect to structural elements: the initial defects manifest themselves in the contact areas between reinforced concrete frames and brick curtain walls. Most occur as a result of renovation or extension of existing buildings, the demolition and reconstruction of neighbouring buildings and differential subsidence of the foundation soil. Cracking and/or detachment of facing material is a defect that can come about as the result of other damage, such as structural failure, or may be the result of poor design choices or construction practices.

\section{Dampness from condensation}

The problem of water condensation within buildings accounts for $8.2 \%$ of the damage cited in our case study and was found to be mainly due to:

- insufficient interior fresh air circulation;

- inadequate thermal insulation of walls and floors;

- thermal bridges;

- external cladding that prevents wall 'breathing'.

- inadequate time to allow wall and floor panels to dry out with respect to the time of cladding. The presence of condensation can compromise not only the performance of the structures concerned, but the liveability of the areas interior to them.

\section{$\underline{\text { Collapse and structural failure }}$}

The collapses and structural failures encountered were mainly partial and largely involved the floors or roofs of old wooden frame buildings, where failure came about through brittle fracture of the beams, often in the vicinity of the supports due to decreasing shear strength. The occurrence of such events was greatly compounded by poor maintenance.

\section{Improper finishing, acoustic insulation and systems malfunctions}

The problems cited in these categories regarded imperfect execution of finishings (facings, floors, fixtures, metalwork), which represented about $10 \%$ of the defects encountered. Such 
flaws can be attributed to poor or downright negligent construction practices on the part of the contracting companies. The lack of sound insulation, which was encountered least often, was frequently the result of inadequate design and/or erroneous choice of materials. Finally, the defects related to systems malfunctions (electrical, heating and plumbing) were often found to be due to a lack of planning and failure to comply with regulations.

A question: "Are defects more frequent in new buildings or in existing ones?"

The survey revealed that over $70 \%$ of all suits regarded existing buildings and that in $47 \%$ of such cases they were filed against the contractors. Moreover, pre-existing buildings are the most prone to errors during maintenance operations (e.g. roofing and façades). This is also because 'maintenance' operations are often undertaken only when damage to the building is already done. Thus, such repairs generally require more difficult and significantly more expensive operations than proper, regular maintenance. Correct maintenance should in fact be foreseen in the design stage, through the specification of building practices, details, materials, components and systems that take account of future maintenance to provide for immediately effective, low-cost control measures.

Moreover, all too often improper or inadequate maintenance accelerates the natural process of building decay and can actually lead to structural consequences: this is the so-called technological degradation of buildings. In fact, the survey also revealed that often too little attention is paid to the interactions between new and old materials. Modern polymer paints, waterproofing and similar elements are applied to the traditional plaster facades of old buildings, but repair and renovation work is often carried out to solve a specific problem without proper assessment of the consequences on the overall integrity of the construction. In the present statistical study, such practices were some of the main cause of defects resulting from renovation works. 


\section{$\underline{\text { Structural alterations. }}$}

The most frequent structural alterations were found in masonry buildings, where the layout of rooms was rearranged or an extension added to the building itself or to an adjacent structure. Often in such cases the consequences manifest themselves only some time later, subsequent to the structure's slow adaptation to its new configuration and loading conditions. Also, the addition of new systems, calling for making grooves in walls or holes in floors, for example, can sometimes produce thermal bridges or routes for leakage, and may even affect the local integrity of structural elements and change their static behaviour.

\section{Defect classification according to construction stages}

In classifying the defects in the I.T.A.s, the technical consultants also inferred the construction stages at which errors leading to the damage occurred, according to the following subdivision, slightly modified with respect to Carper's proposal (Carper, 2002):

- design errors;

- negligent work supervision;

- improper construction techniques;

- unjustified divergence from the design during execution;

- errors by other parties (e.g., improper maintenance or use).

Errors made during a building's conception were responsible for the damage in about $36 \%$ of cases and involved both structural and architectural aspects. The former can be attributed essentially to errors in judgment due to modelling errors or poor understanding of structural behaviour. The latter instead resulted from failure to correctly evaluate the material properties and any potential incompatibilities (often due to the widespread tendency to favour aesthetics over structural aspects). Errors of the kind are frequently committed in planning maintenance, structural retrofitting operations or during renovation of existing buildings. Together with 
design flaws, errors in execution, which occurred in nearly $43 \%$ of cases, were the source of most of the construction defects encountered. Indeed, quite frequently design errors and construction errors occurred in conjunction.

In general, the emergence of errors in execution is closely linked to inadequate implementation of the design, often involving inappropriate construction practices. In other cases, however, uncalled for changes in the design specifications during construction distort the design previsions. This does not however diminish the fact that most of the failures were due exclusively to deficient or negligent execution, such as haste in completing the work (e.g., not respecting the prescribed concrete setting and hardening times, etc.).

Errors by other parties, which account for the remaining $21 \%$, are those attributable to intervention, after completion of the building, by individuals or companies uninvolved in the processes of design and construction. These include both mismanagement and poor maintenance by the owner. Indirect actions consequent to operations on nearby buildings are also considered, such as excavations or hydro-geological modifications that change the groundwater level, for example.

\section{A TWO-DECADE COMPARISON}

As stated, one aim of the study has been to look at the evolution of building practices over the years, in particular to see how technological advances have affected the quality of construction in recent years. To this end, we compared the results obtained in the current study with those from a similar survey carried out on legal suits for damages during the 90 s, also in the district of Pisa. From the results obtained it is clear that the types of defects and their percentage occurrences have remained surprisingly similar over the past twenty years, especially with regard to the categories of the most frequent problems: water damage, cracking and condensation. This can be clearly seen by comparing graphs in figures 6 and 12, which 
respectively show the percentage distribution of construction defects for the decade 2000-2011 and that for the 20-year period 1990-2011. Such a finding leads to the conclusion that although great advances have been made in construction technologies and scientific knowledge over the last two decades, their use has not been properly disseminated: most engineers, architects and builders prefer to carry on with their timeworn construction practices and only modify their approach to building when new regulations are issued (such as seismic codes).

A second interesting finding is illustrated in the graphs of figure 13, which shows the percentage distribution of the construction stages deemed responsible (in the I.T.A.s) for errors for both the periods 1990-1999 and 2000-2011 (as per the conclusions of technical consultants). Note that in the last decade there has been a certain increase in the percentage of errors attributable to the design stage, rather than from interference by third parties, while the percentage of errors in construction has remained unchanged. This probably depends on improvements in investigative techniques, which are better able to identify the causes, and thereby avoid the simple solution of imputing liability to a lack of maintenance.

Fig. 12. Percentage distribution of construction defects reported in the district of Pisa for the period $1990-2011$.

The statistical investigation was carried out in a specific area of Italy, with a level of development of construction techniques that is however representative of the entire country. Nonetheless, we do not have sufficient evidence to extend the results to other European countries. However, the progressive harmonization of design and construction processes and products in the European standards $(\mathrm{EN})$ begun in the 80 s enable considering this study a sound preliminary basis for future research.

Fig. 13. Percentage distribution of the stages of the design/construction process giving rise to errors from 1990 to 1999 and from early 2000 to 2011 


\section{CONCLUSIONS AND FURTHER DEVELOPMENTS}

This study outlines a rather alarming picture of current construction practices (at least in Tuscany). It seems that the advances made in building engineering, in terms of materials, resources and knowledge, have not been not matched by any such progress in the actual construction of buildings. Thoroughly analyzing the causes of this phenomenon would be a complex task, but one aspect certainly stands out: the current organization of the design process. Building projects are often not addressed in their entirety, but divided into specialized components requiring special skills (planning, architectural appearance, facilities, equipment, finishing) with little or no supervised coordination during the design process. Indeed, it often happens that individual aspects wind up schematically superimposed or, as in the case of systems equipment, even considered a posteriori, sometimes planned only to correct design flaws (e.g., building layout, insulation and thermal inertia).

Secondly, there has been a steadily increasing trend to opt for poor quality materials. This, together with the failing of entrepreneurship and professionalism in the construction industry have helped accelerate the phenomenon of the qualitative decay of new buildings. The study has revealed that over a twenty-year period the percentages of each of the flaws detected have remained substantially unchanged, demonstrating the continuing adoption of poor construction practices, indifferent, especially over the last ten years, to the considerable progress that has been made, not only in our knowledge of engineering, materials and construction systems, but in training our workforce to be qualified, conscientious builders.

The proposed classification could be implemented in an automatic procedure, which would call for the following information on each individual case:

- type of building (steel, r.c., masonry, etc.) and its intended use (residence, commercial or industrial warehouse, factory, etc.);

- period of construction and any renovations; 
- developer / designer / work supervisor / builder / inspector;

- $\quad$ origins of the damage according to plaintiff, defendant, and third parties involved;

- court-appointed consultant's estimate of the direct damages;

- direct damages in terms of percentage of the building's value as determined by the court-appointed consultant.

A procedure for anonymous, automatic classification to be followed for every court sentence would represent a highly useful source of information. In just a short time statistically meaningful datasets could be compiled to help us better understand how failures in the construction processes occur - information that would furnish an invaluable guide for future research, education and professional training to help address this true emergency in the building industry.

\section{BIBLIOGRAPHY}

- Acocella, A., and Pisani, M. (1994). "The roof as architectural element", Costruire in Laterizio, 42, Tecniche Nuove Ed., Milano (Italy).

- Arangio, S., Bontempi, F., and Ciampoli, M. (2010). "Structural integrity monitoring for dependability", Structure and Infrastructure Engineering, online from 6 April 2010, DOI: $10.1080 / 15732471003588387$.

- Augenti, N. (ed.) (2009). IFCRASC'09 - $1^{\text {st }}$ Meeting on Forensic Engineering, Collapses, Structural Reliability and Reinforcement, Ed. Doppiavoce, Napoli.

- Augenti, N., and Sassu, M. (eds.) (2012). IF-CRASC'12 - $2^{\text {nd }}$ Meeting on Forensic Engineering, Collapses, Structural Reliability and Reinforcement, Ed. Doppiavoce, Napoli.

- Bosela, P., Carper, K. L., Delatte, N., Rens, K., and Sutterer, K. (2007). "Findings from Workshops on Failure Case Studies in the Civil Engineering and Engineering Mechanics 
Curriculum". Proc. of the Annual Conference, American Society for Engineering Education, Honolulu, Hawaii.

- Carper, K. L. (2001). Why Buildings Fail, National Council of Architectural Registration Boards (NCARB), Washington DC.

- Carper, K. L., (2002). "Lessons Architects Can Learn from Failures". In Crolli e Affidabilita delle Strutture Civili (Structural Failures and Reliability of Civil Structures), Roberto Gori ed., Ed. Libreria Cortina, Padova, Italy, 3-22.

- Cellesi, L., De Falco, A., and Sassu, M. (2012). "Interim Technical Assessments and disputes on civil constructions in the district of Pisa". Proc. $2^{\text {nd }}$ conference IF-CRASC'12, Pisa, 157166.

- Chong, W.K., and Low, S.P. (2006). "Latent Building Defects: Causes and Design Strategies to Prevent Them". Journal of Performances and Constructed Facilites. 20(3), 213-221.

- Cirillo, E. (1985). Wellness housing and brick masonry, brick Building, n.2, PUBLISHING Faenza, Faenza (RA).

- De Witt, W., Geddes, L., Johnson, F., and Reader, L. (2001). "A master of science curriculum in forensic engineering". 31th ASEE/IEEE Frontiers in Education Conference, Reno, NV.

- Dörner, D. (1996). The logic of failure: Recognizing and Avoiding Error in Complex Situations, Metropolitan books, NY.

- Drdàck, M.F, and Kratena, J. (2000). "Forensic Practice in Czech Republic". Proc. of 2nd Congress Forensic Engineering, ASCE, Reston, VA.

- Feld, J., and Carper, K.L. (1997). Construction Failure, $2^{\text {nd }}$ edition, John Wiley \& Sons, Inc.

- Gucci, N., Paoli, A., and Tuoni, G. (1997). "The effects of thermo hygrometric rain on the walls". Costruire in laterizio, 57, 213-218. 
- Gucci, N. (1998). "Some reflections on the process of building design". The Italian Engineer, 295.

- Gucci, N., Bartolo, P., and Sassu, M. (2002). "Survey on construction defects in buildings in western Tuscany through the study of legal". Proc. of the National Conference on Technology and Law - the forensic engineering, the tasks and responsibilities in the construction process Venice, 5-6 December 2002.

- Gucci, N., De Falco, A., and Sassu, M. (2003). "Litigation judicial or defects in buildings" L'Edilizia, 129, 60-65.

- Kaminetzky, D. (1991). Design and Construction Failures: Lesson from Forensic Investigations, Mc Graw Hill, Inc., New York, NY.

- Matousek, M., and Schneider, J. (1976). Untersuchungen zur Struktur des Sicherheitsproblems bei Bauwerken, Bericht n.59, Birkhauser Verlag, Basel und Stuttgart,

- Ratay, R.T. (2000). Forensic Structural Engineering Handbook, Mc Graw Hill.

- Sassu, M., and Ponzone, P., (2009). "Case studies of litigation on university constructions: the amicable agreement and other solving instruments". Proc. $1^{\text {st }}$ conference IFCRASC'09, Neaples, $167-177$.

- Schneider, J. (1997). Introduction to Safety and Reliability of Structures, IABSE-AIPCIVBH, Zurich.

- Yates, J.K., and Lockley, E.E. (2002). "Documenting and Analyzing Construction Failures". Journal of Construction and Engineering Management, 128(1), 8-17.

- Zaffagnini, M. (1991). Design in the construction process; reality as a backdrop for residential construction, LUIGI Parma, Bologna. 


\begin{tabular}{|c|c|c|c|c|c|c|c|c|c|c|c|c|c|c|c|c|c|c|c|c|}
\hline \multicolumn{21}{|c|}{ PISA AND PROVINCE } \\
\hline \multirow{2}{*}{\multicolumn{2}{|c|}{$\frac{\text { YEAR }}{\text { ITA I.D. no. }}$}} & \multicolumn{2}{|c|}{2000} & \multicolumn{4}{|c|}{2001} & \multicolumn{3}{|c|}{2002} & \multicolumn{10}{|c|}{2003} \\
\hline & & 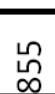 & $\underset{\text { Iี }}{\text { I }}$ & $\stackrel{\mathcal{F}}{\mathcal{m}}$ & חั & $\hat{n}$ & ন্ & ס్ & 㞫 & 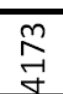 & ก & ஜू & 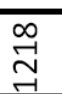 & 命 & 奪 & م్ & $\underset{m}{\hat{m}}$ & 욜 & $\begin{array}{l}\text { Ln } \\
\infty \\
0 \\
m\end{array}$ & 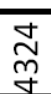 \\
\hline & of defects encountered & 1 & 2 & 3 & 1 & 2 & 1 & 1 & 2 & 2 & 1 & 1 & 2 & 1 & 1 & 1 & 1 & 5 & 1 & 1 \\
\hline \multirow{7}{*}{ 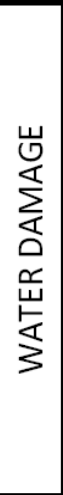 } & $\begin{array}{l}\text { BASEMENT OR GROUND } \\
\text { FLOOR }\end{array}$ & & & & & & & & & & & & & & & & & & & \\
\hline & HIGH WALLS & & & & & & & & & & & & & & & & & & & \\
\hline & ROOF TERRACES & & & & & & & & & & & & & & & & & & & \\
\hline & PITCHED ROOFS & & & & & & & & & & & & & & & & & & & \\
\hline & BALCONIES & & & & & & & & & & & & & & & & & & & \\
\hline & \begin{tabular}{|l|} 
PLUMBING LEAKS OR \\
BURSTS
\end{tabular} & & & & & & & & & & & & & & & & & & & \\
\hline & OTHER & & & & & & & & & & & & & & & & & & & \\
\hline \multirow{5}{*}{ 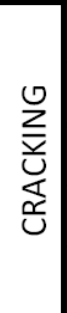 } & PLASTERWORK & & & & & & & & & & & & & & & & & & & \\
\hline & FLOORS & & & & & & & & & & & & & & & & & & & \\
\hline & WALLS & & & & & & & & & & & & & & & & & & & \\
\hline & FLOOR STRUCTURES & & & & & & & & & & & & & & & & & & & \\
\hline & BEAMS/COLUMNS/ARCHES & & & & & & & & & & & & & & & & & & & \\
\hline \multicolumn{21}{|c|}{ SYSTEMS MALFUNCTION } \\
\hline \multicolumn{21}{|c|}{ DEFECTIVE FINISHING } \\
\hline \multicolumn{21}{|c|}{ CONDENSATION DAMPNESS } \\
\hline \multicolumn{21}{|c|}{ ACOUSTIC NON-COMPLIANCE } \\
\hline \multicolumn{21}{|c|}{ PARTIAL OR TOTAL COLLAPSE } \\
\hline & RUCTURAL SETTLEMENTS & & & & & & & & & & & & & & & & & & & \\
\hline
\end{tabular}




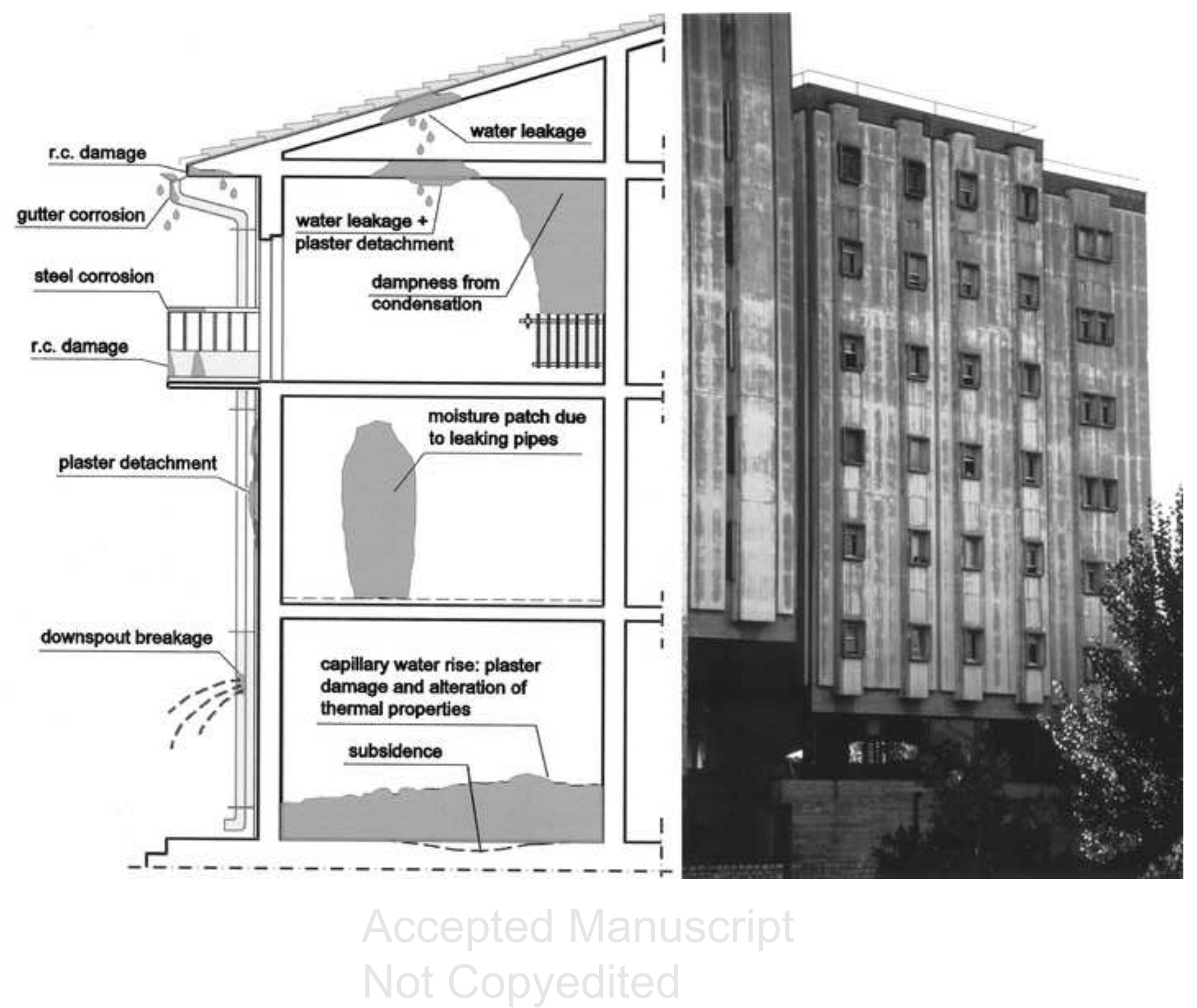

Copyright 2013 by the American Society of Civil Engineers

J. Perform. Constr. Facil. 


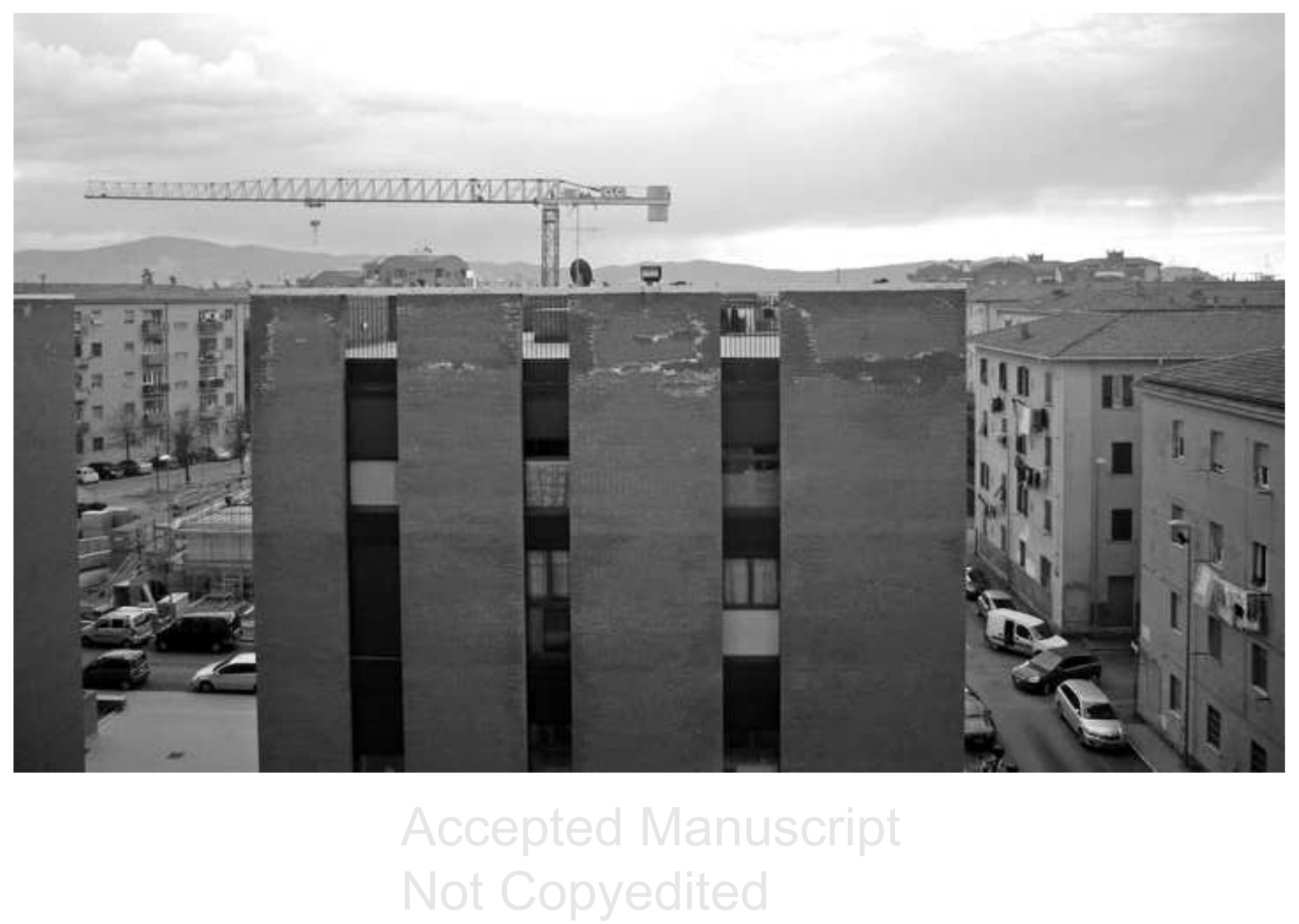

Copyright 2013 by the American Society of Civil Engineers 


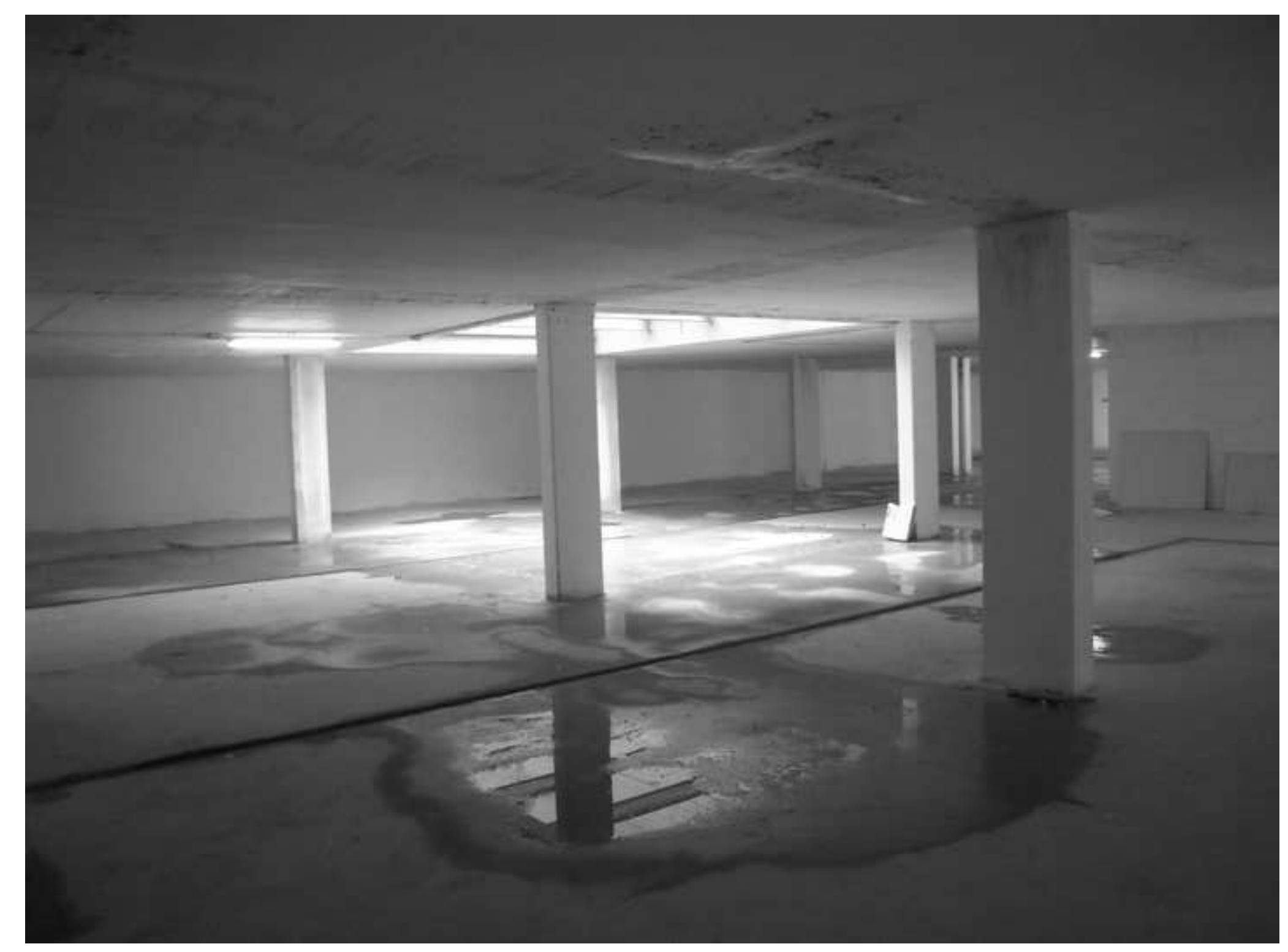

\section{Accepted Manuscript} Not Copyedited

Copyright 2013 by the American Society of Civil Engineers 
Journal of Performance of Constructed Facilities. Submitted June 7, 2013; accepted October 11, 2013; posted ahead of print October 14, 2013. doi:10.1061/(ASCE)CF.1943-5509.0000520

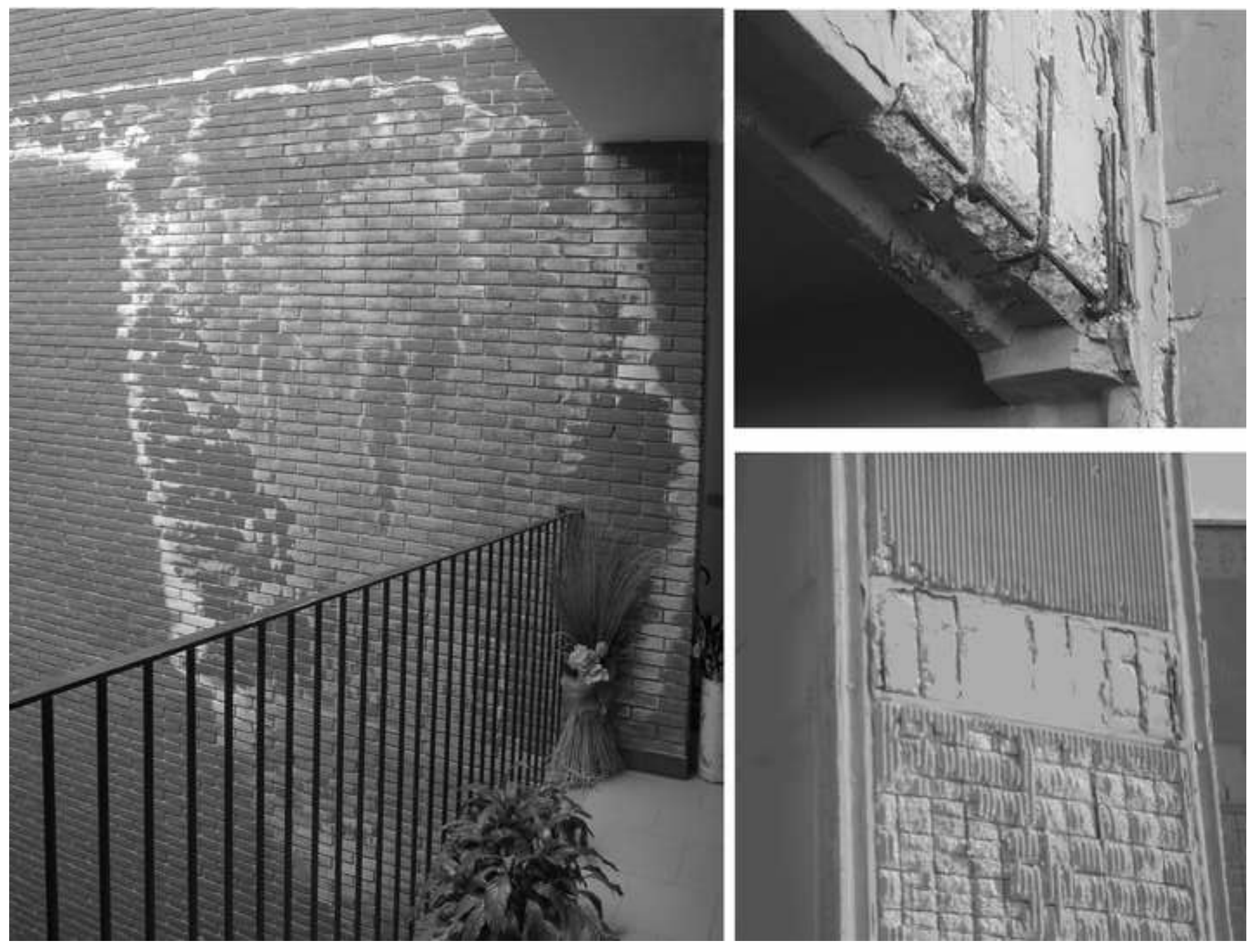

Accepted Manuscriot

NOt OOMNOOIIOO

Copyright 2013 by the American Society of Civil Engineers 

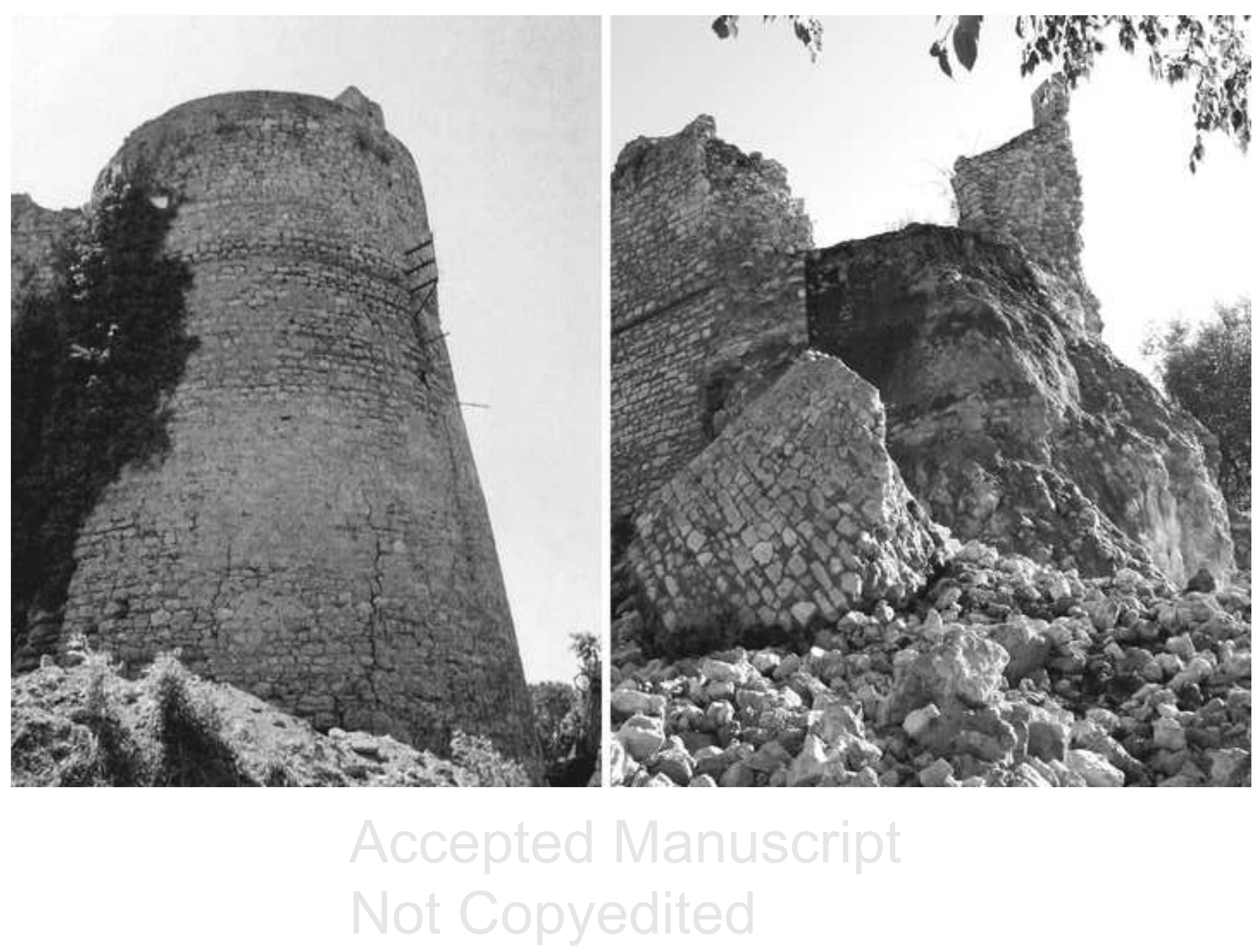

Copyright 2013 by the American Society of Civil Engineers 


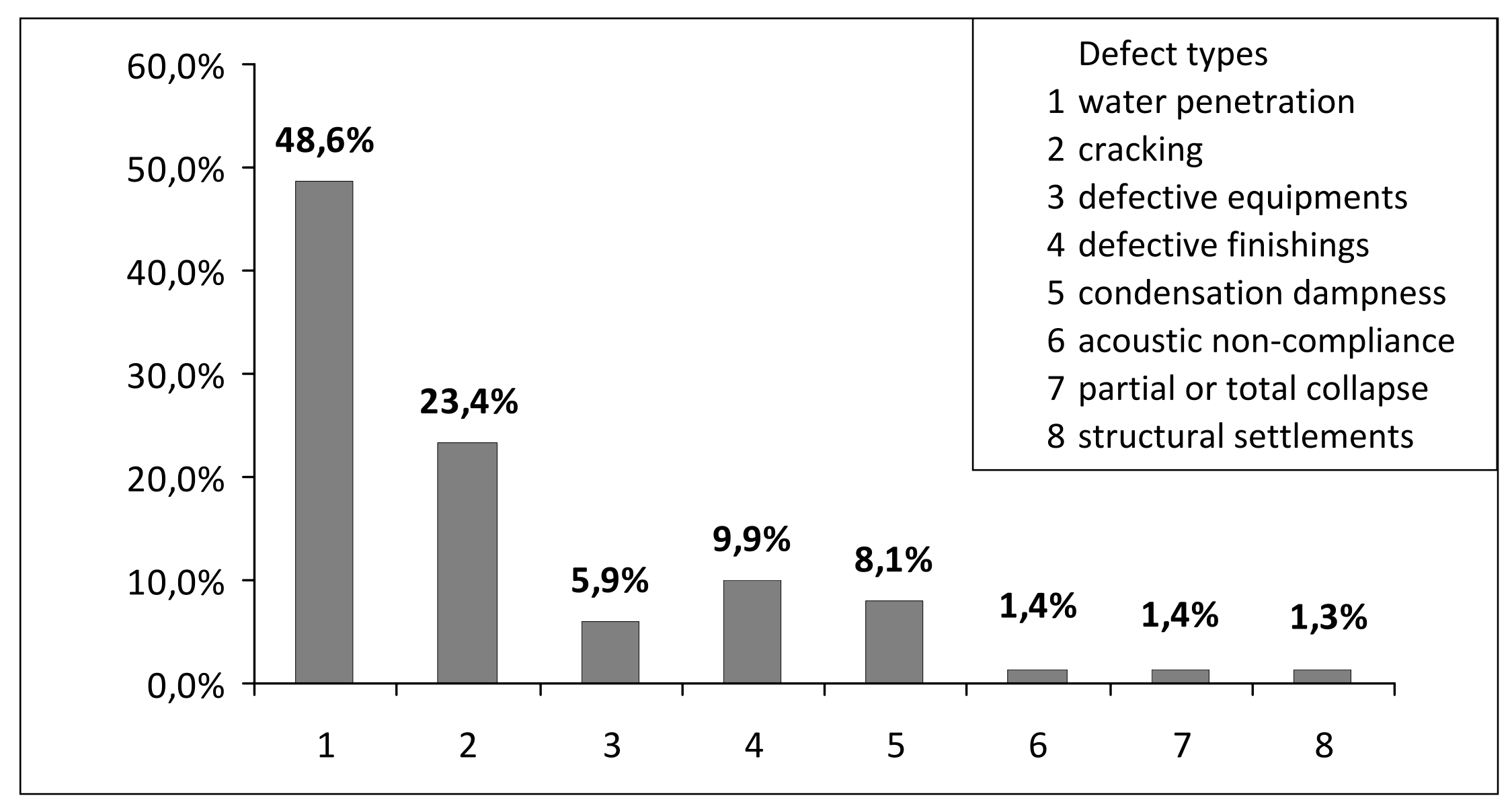




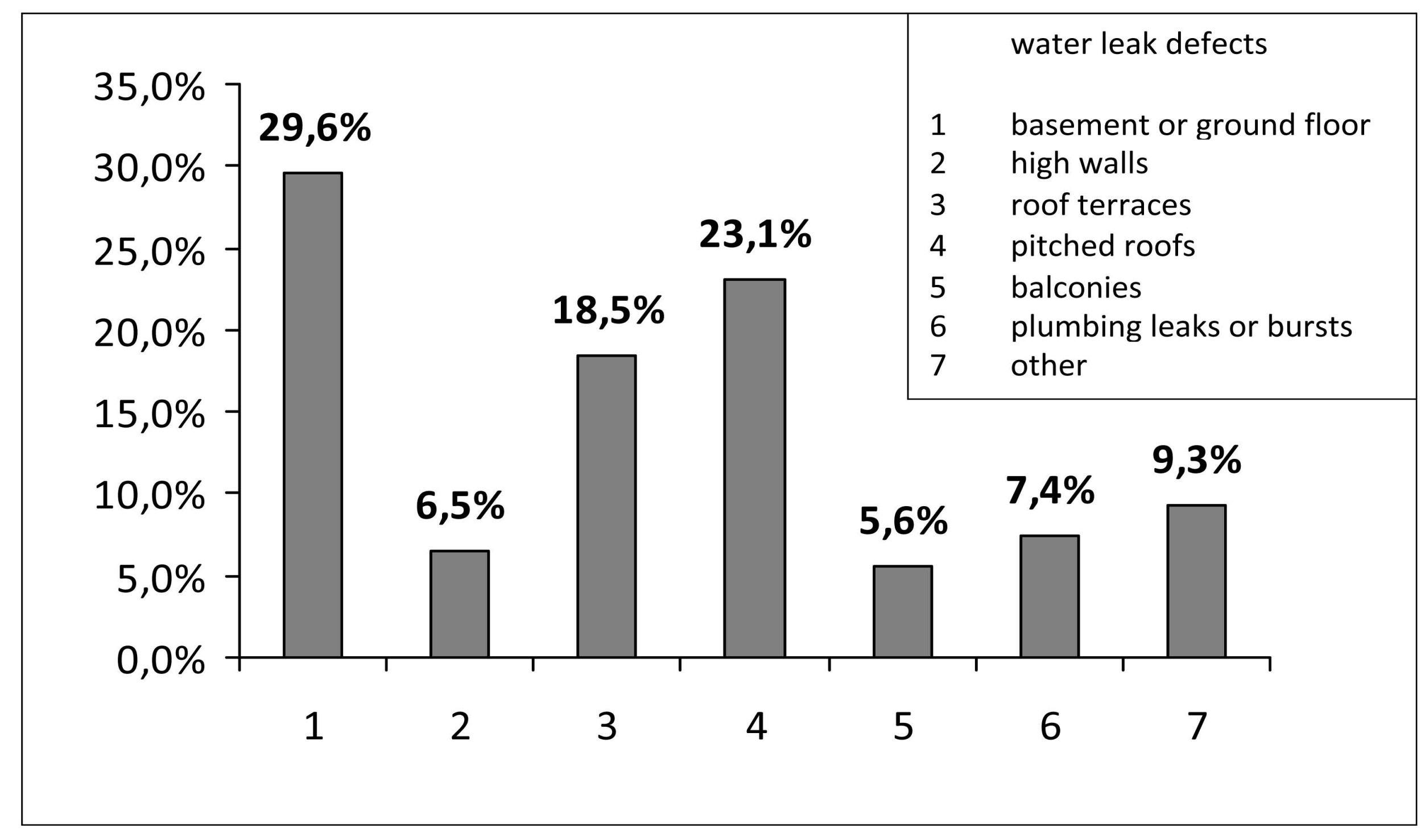




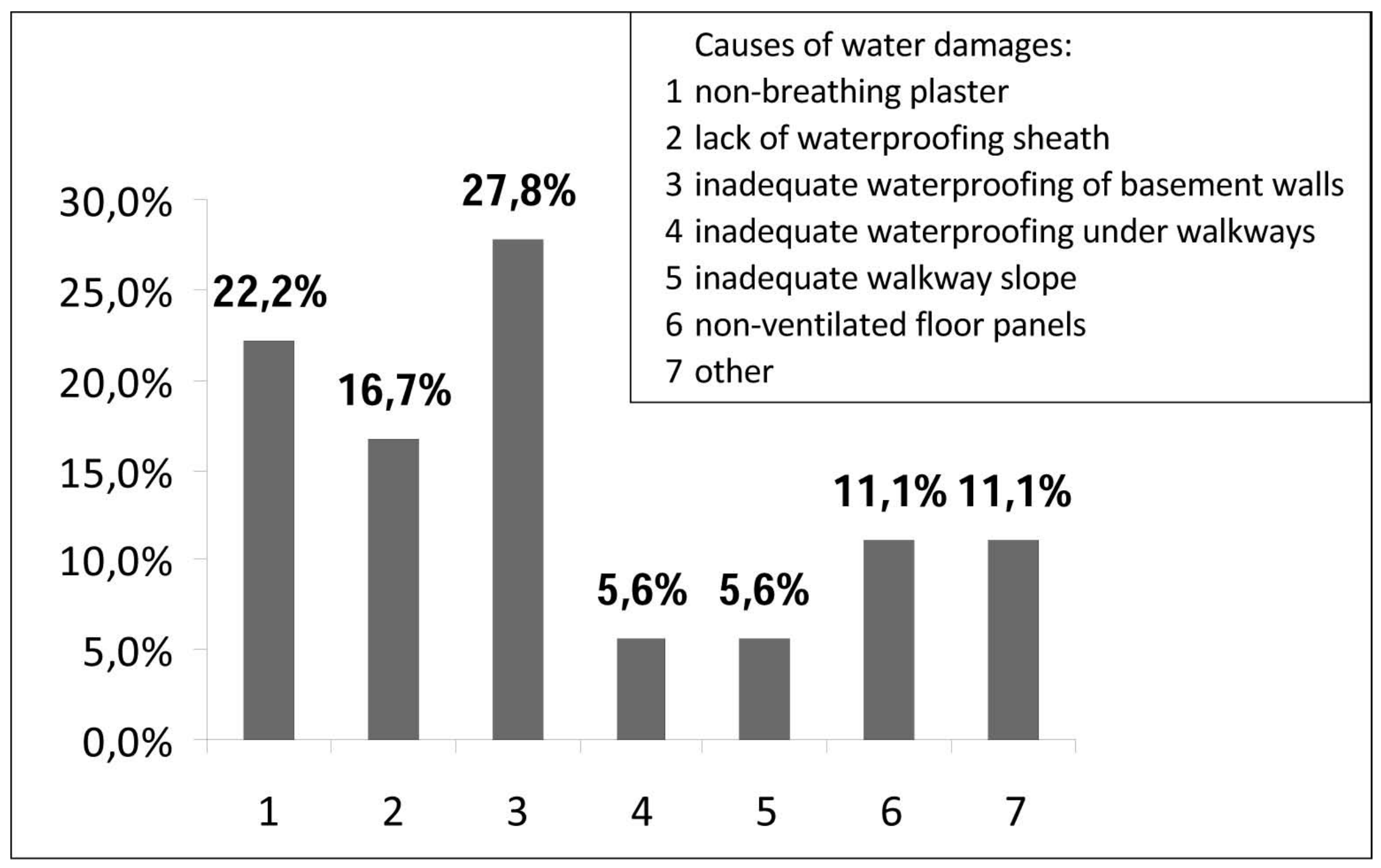




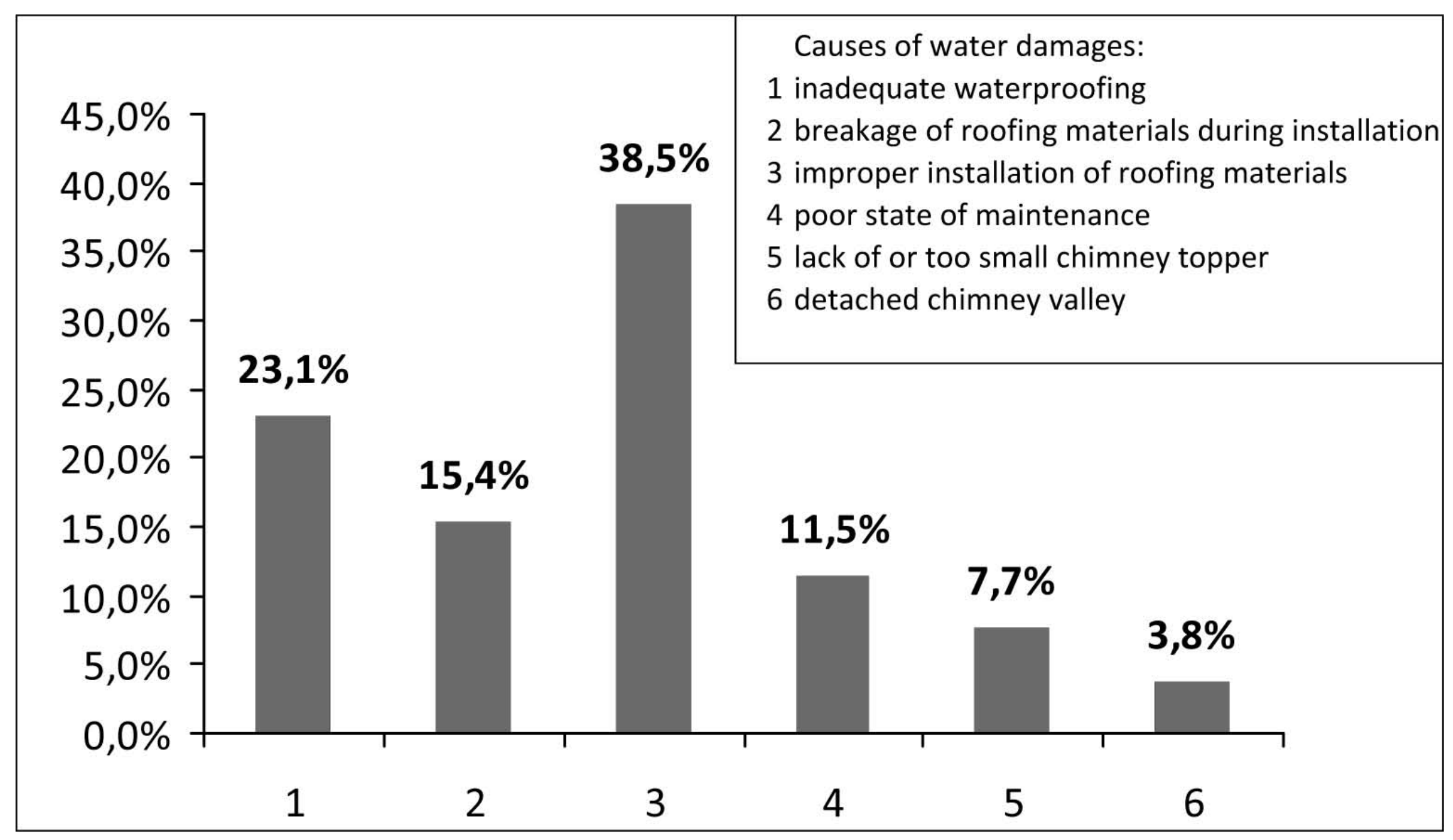




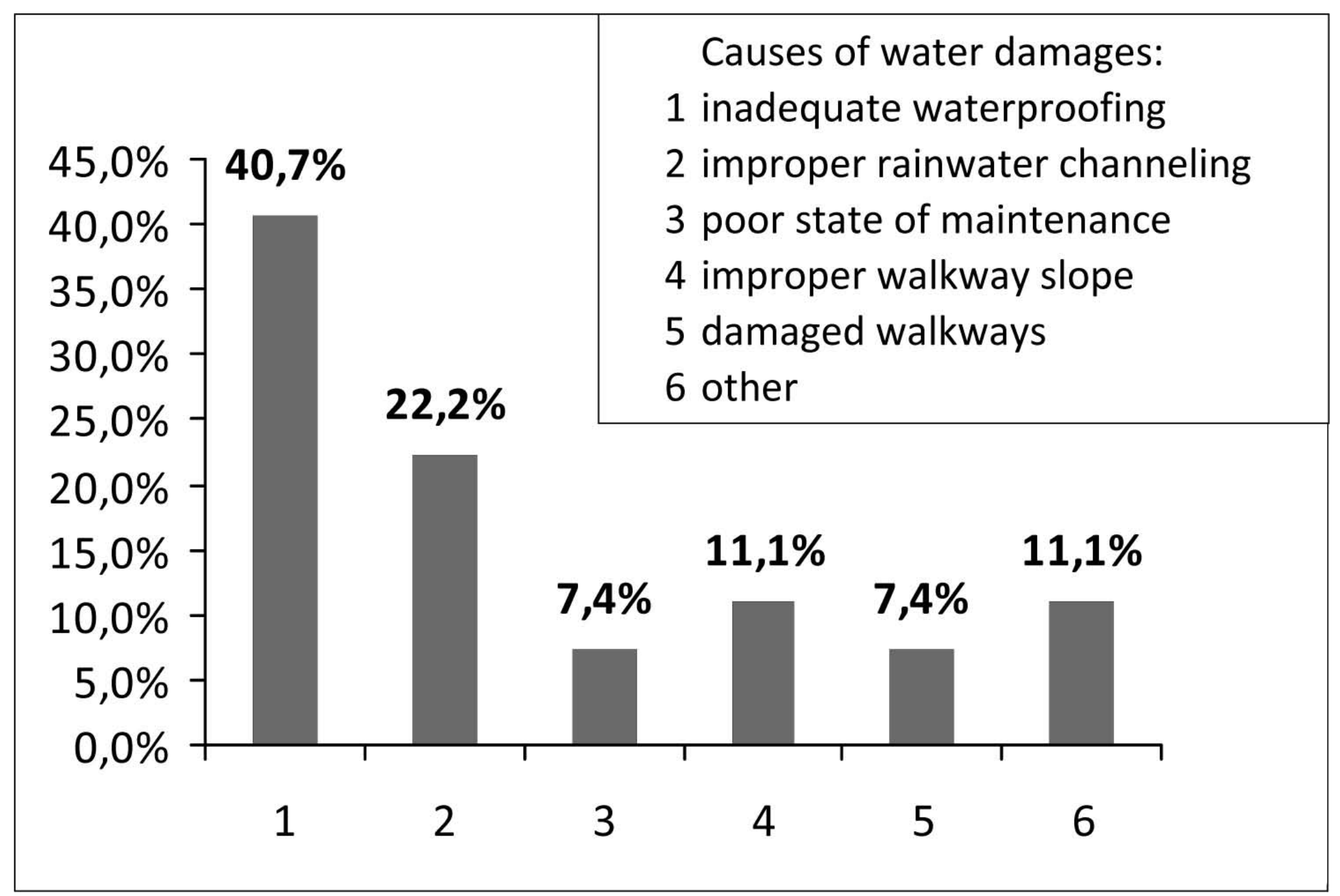




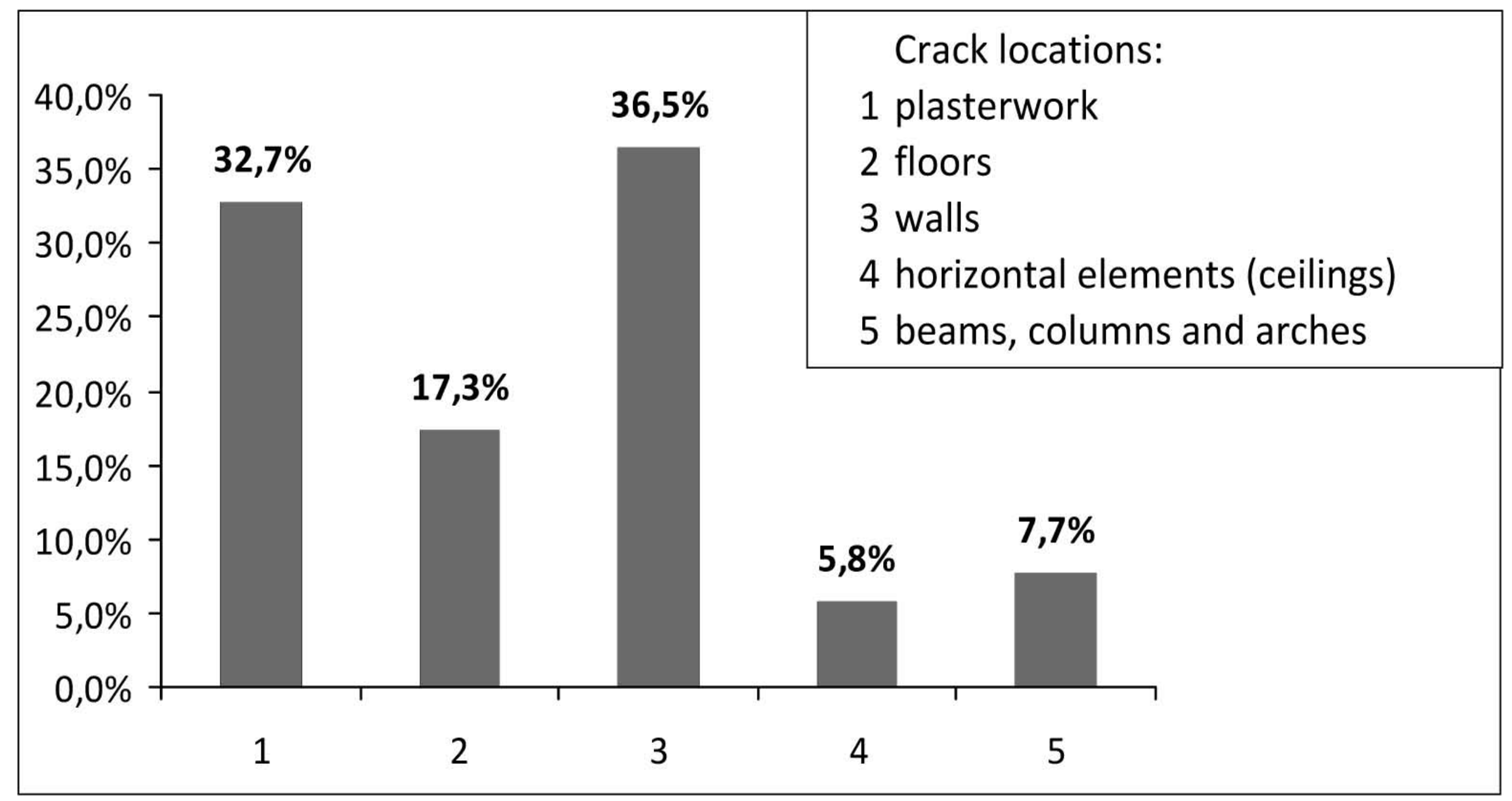




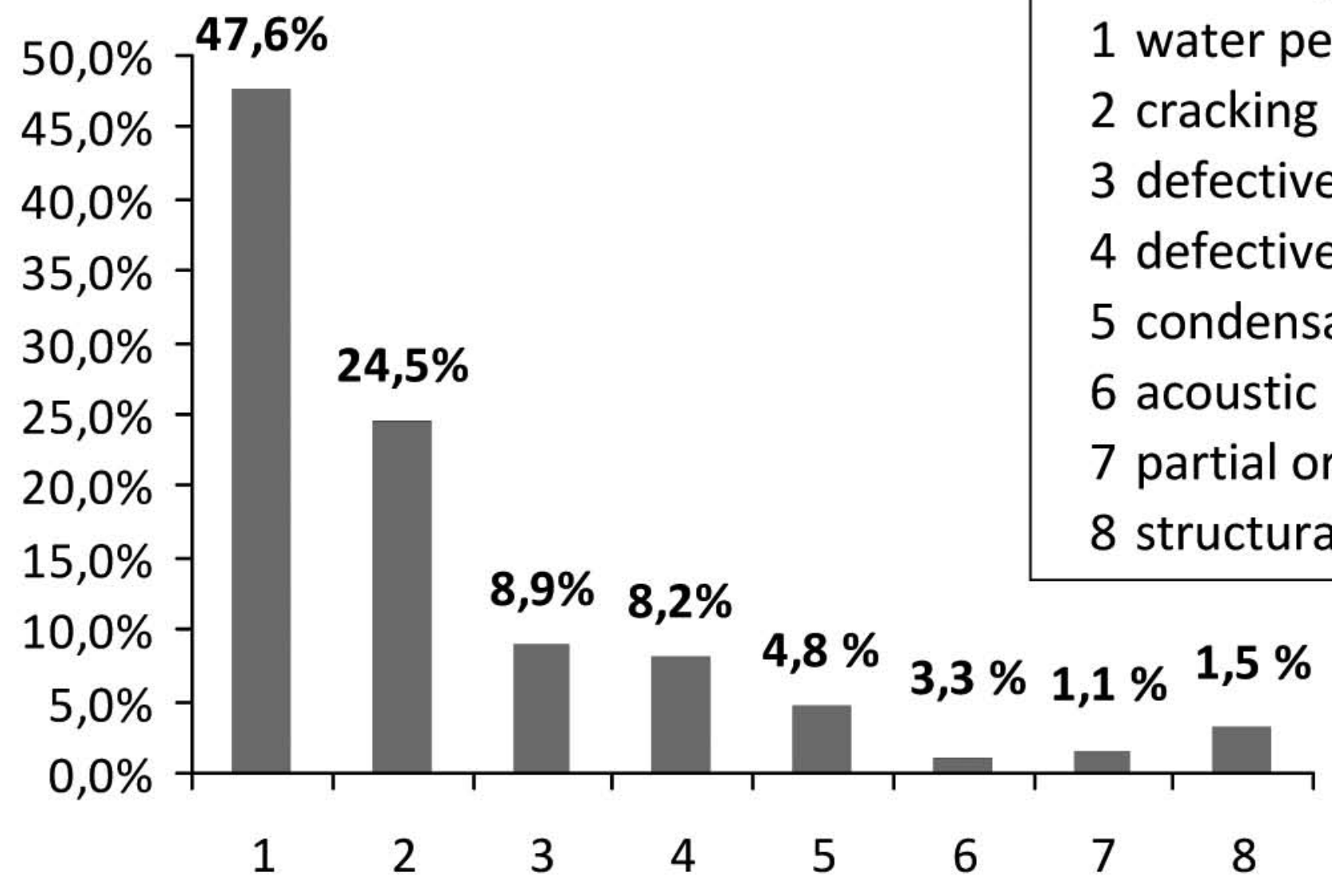


FROM 1990 to 1999

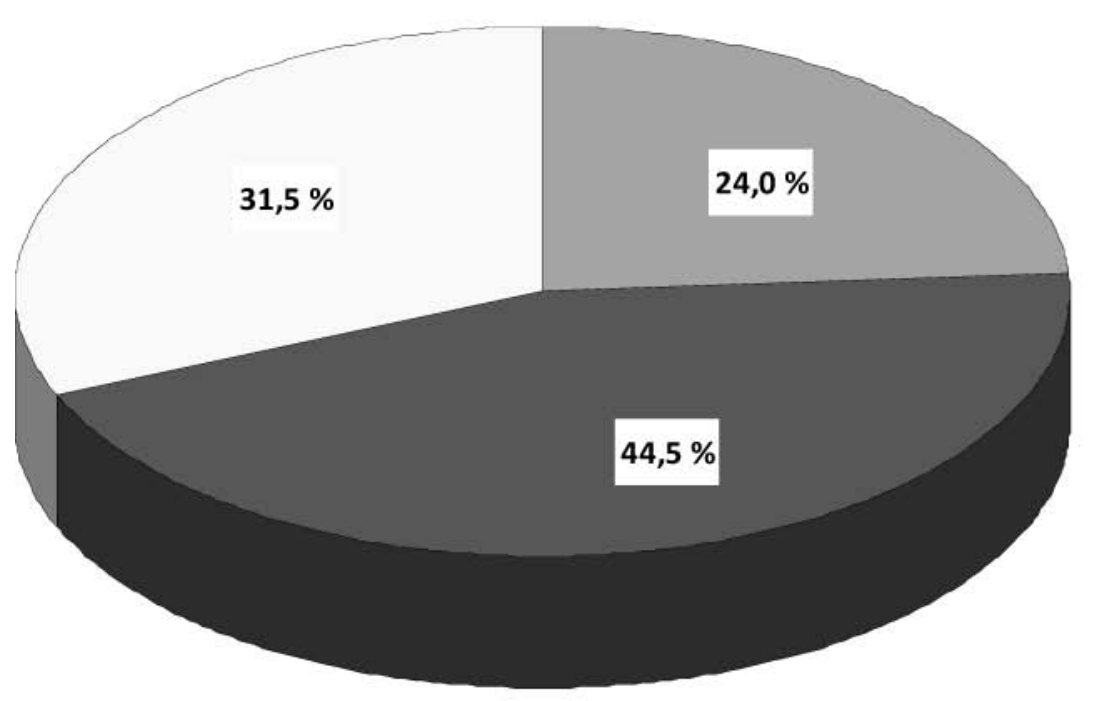

FROM 2000 to 2011

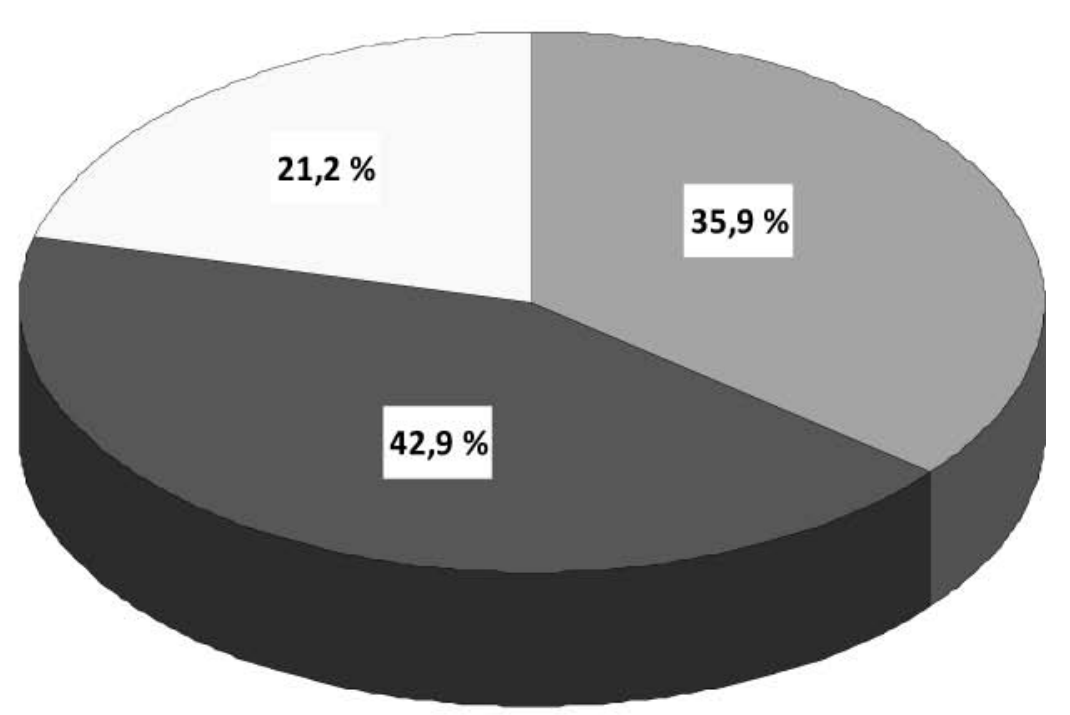

$\square 1$. errors in design or during inspection works

- 2 . constructive defects

$\square 3$. lack or defects in maintenance

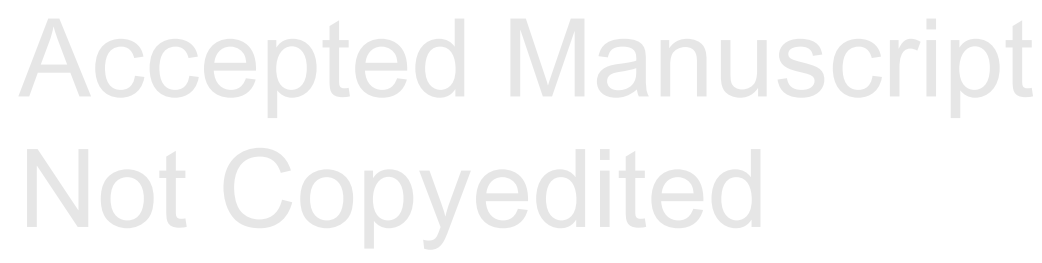

Copyright 2013 by the American Society of Civil Engineers 
Fig. 1 a) Most frequent construction defects linked to the presence of water; b) Surface decay due to driving rain

Fig. 2. Modern roof terrace (with water damage) and surrounding traditional pitched roofs (without problems)

Fig.3. Improper disposal of rainwater in underground garage and efflorescences on an r.c. ceiling.

Fig.4. Erroneous selection of clay units (left), concrete (upper right) or plaster (lower right)

Fig.5. Unassessed structural integrity of historical tower (collapsed after heavy rain)

Fig. 6: Percentage distribution of construction defects reported in the district of Pisa $2000-2011$.

Fig. 7. Percentage distribution of water leak defects according to source.

Fig. 8. Percentage distribution of the major causes of water damage to basement and ground floor.

Fig. 9. Percentage distribution of main causes of leakage in pitched roofs.

Fig. 10. Percentage distribution of main causes of water damage in flat roofs.

Fig. 11. Partial incidence of crack location.

Fig. 12. Percentage distribution of construction defects reported in the district of Pisa for the period $1990-2011$.

Fig. 13. Percentage distribution of the stages of the design/construction process giving rise to errors from 1990 to 1999 and from 2000 to 2011

Table 1. Defect types reported in each ITA (2000 to 2003 extract). 